\title{
Outcomes following resuscitative thoracotomy for abdominal exsanguination, a systematic review
}

\author{
Michael Hughes ${ }^{1 *}$ (D) and Zane Perkins ${ }^{2}$
}

\begin{abstract}
Background: Resuscitative thoracotomy is a damage control procedure with an established role in the immediate treatment of patients in extremis or cardiac arrest secondary to cardiac tamponade however Its role in resuscitation of patients with abdominal exsanguination is uncertain.
\end{abstract}

Objective: The primary objective of this systematic review was to estimate mortality based on survival to discharge in patients with exsanguinating haemorrhage from abdominal trauma in cardiac arrest or a peri arrest clinical condition following a resuscitative thoracotomy.

Methods: A systematic literature search was performed to identify original research that reported outcomes in resuscitative thoracotomy either in the emergency department or pre-hospital environment in patients suffering or suspected of suffering from intra-abdominal injuries. The primary outcome was to assess survival to discharge. The secondary outcomes assessed were neurological function post procedure and the role of timing of intervention on survival.

Results: Seventeen retrospective case series were reviewed by a single author which described 584 patients with isolated abdominal trauma and an additional 1745 suffering from polytrauma including abdominal injuries. Isolated abdominal trauma survival to discharge ranged from 0 to $18 \%$ with polytrauma survival of $0-9.7 \%$ with the majority below $1 \%$. Survival following a thoracotomy for abdominal trauma varied between studies and with no comparison non-intervention group no definitive conclusions could be drawn.

Timing of thoracotomy was important with improved mortality in patients not in cardiac arrest or having the procedure performed just after a loss of signs of life. Normal neurological function at discharge ranged from 100 to $28.5 \%$ with the presence of a head injury having a negative impact on both survival and long-term morbidity.

Conclusions: Pre-theatre thoracotomy may have a role in peri-arrest or arrested patient with abdominal trauma. The best outcomes are achieved with patients not in cardiac arrest or who have recently arrested and with no head injury present. The earlier the intervention can be performed, the better the outcome for patients, with survival figures of up to $18 \%$ following a resuscitative thoracotomy. More high-quality evidence is required to demonstrate a definitive mortality benefit for patients.

\footnotetext{
* Correspondence: michael.hughes2@nhs.net

${ }^{1}$ Scarborough Hospital, York Teaching Hospital NHS Trust, Woodlands drive,

Scarborough YO12 6QL, UK

Full list of author information is available at the end of the article
}

(c) The Author(s). 2020 Open Access This article is distributed under the terms of the Creative Commons Attribution 4.0 International License (http://creativecommons.org/licenses/by/4.0/), which permits unrestricted use, distribution, and reproduction in any medium, provided you give appropriate credit to the original author(s) and the source, provide a link to the Creative Commons license, and indicate if changes were made. The Creative Commons Public Domain Dedication waiver (http://creativecommons.org/publicdomain/zero/1.0/) applies to the data made available in this article, unless otherwise stated. 


\section{Background}

The management of the peri-arrest or arrested patient following major trauma is controversial with poor outcomes in both civilian and military practice $[1,2]$. Current guidelines advocate initiating cardiopulmonary resuscitation, intubation and bilateral thoracostomies followed by rapid transfer to theatre and if available, a range of advanced procedures including a thoracotomy for specific injuries [3].

A thoracotomy is referred to by a variety of names in periarrest or arrested patients depending on the physical location it is performed and the physiological status of the patient (e.g. resuscitative thoracotomy, emergency department thoracotomy etc) $[4,5]$. It is the subject of intense debate and its role within trauma management, especially in blunt trauma, is not certain. However, the procedure is included in the European resuscitation council guidelines for traumatic cardiac arrest for both penetrating and blunt trauma with survival rates of $6-7 \%$ reported by several studies for those suffering from penetrating chest injuries, demonstrating the best outcomes [6-8].Cross-clamping of the thoracic aorta in order to arrest bleeding and improve blood flow proximal to the clamp is a recognised part of the procedure [9]. This is a manoeuvre used both in and out of the operating theatre and is specifically applied to those with intrabdominal trauma in some circumstances, gaining proximal control of arterial bleeding via the chest cavity [9]. The role of a thoracotomy in abdominal trauma assumes that arrest is secondary to hypovolemia due to ongoing haemorrhage and thus by temporarily controlling this before definitive management can be instigated, patient outcomes can be improved. This theory has been reinforced by reports that traumatic cardiac arrest is a "low flow state" rather than a cessation of cardiac activity suggesting that rapid intervention to control haemorrhage may be of benefit [10].

Although patient's with abdominal trauma presenting to UK hospitals have benefited from improved mortality following the introduction of major trauma networks and centralisation of specialist services, survival in this subset of peri arrest patients continue to be poor [11]. It has been demonstrated that patient's requiring a laparotomy that present to hospital hypotensive have poor outcomes. Mortality as high as $46 \%$ has been reported, with prolonged time to theatre with ongoing hypotension worsening mortality further. However, the role of a thoracotomy in abdominal trauma has not been fully explored [12-14].

Timing of resuscitative thoracotomy is important as there is a demonstrated correlation between early intervention and improved mortality [15]. Protocols have been developed for those in traumatic cardiac arrest with a 10 min "cut off" from loss of signs of life, after which a thoracotomy should not be performed, being used by some institutions such as the London Helicopter Emergency Medical Service [16]. Guidelines differentiate between blunt and penetrating trauma advocating a 10-15-min window for intervention depending on the mechanism of injury [3]. A resuscitative thoracotomy can be performed in both the pre-hospital and emergency department setting giving the potential for the intervention to be performed earlier outside of an operating theatre.

Although survival from a procedure is the ultimate end point, the quality of life for patients afterwards is also essential to consider. Neurological outcomes following resuscitative thoracotomy are variable. In patient undergoing the procedure in the pre-hospital environment following penetrating trauma after a short period of time in cardiac arrest outcomes were described as good however, in some cases patients never recover normal neurological function [17-19].

Comparing the outcomes of a thoracotomy to no thoracotomy in abdominal trauma is difficult as little data is available. The Eastern Association for the Surgery of Trauma have made estimates of survival based on expert opinion [20]. Survival varies depending on the presence of signs of life and mechanism of injury (penetrating Vs blunt). In patients presenting to the emergency department with a pulse and evidence or suspicion of penetrating extra thoracic trauma the expert working group suggest that the chance of survival following an emergency thoracotomy was $15.6 \%$ compared to $1.7 \%$ without. Patient's with the same pattern of injury but arriving without a pulse had an estimate average survival of $2.9 \%$ following a thoracotomy and $0.1 \%$ without.

In blunt trauma the expert group estimated that patient survival was much lower when suffering from an extra thoracic pattern of injury when compared to penetrating trauma but still felt emergency thoracotomy made a difference to survival. In those arriving with a pulse, survival following a thoracotomy was $4.6 \%$ compared to $0.5 \%$ without. Patient arriving without a pulse following blunt trauma had an estimated survival of $0.7 \%$ with a thoracotomy compared to $0.001 \%$ without.

The aim of this systematic review was to estimate the overall change in mortality for adults with clinically diagnosed exsanguinating abdominal haemorrhage treated with resuscitative thoracotomy before entering theatre, based on available evidence and then compare this with the expert group estimates of survival.

\section{Hypothesis}

Resuscitative thoracotomy does not improve mortality, quantified as survival to discharge, in blunt or penetrating abdominal trauma in contrast to expert opinion estimating outcomes following current conventional management.

\section{Aims}

- Identify current use of pre-hospital and emergency department resuscitative thoracotomy in intra- 
abdominal trauma (either isolated or part of multiple injuries)

- Evaluate overall outcomes in intervention group and focus specifically on survival to discharge with secondary assessment of timing of intervention and neurological outcome in survivors.

- Contrast outcomes of patient's undergoing resuscitative thoracotomy with expert opinion of survival with patient's suffering similar injuries but not having the intervention.

\section{PICOS}

P Patient with suspected haemorrhagic shock secondary to intra-abdominal trauma (either isolated or as a combination of injuries) in a peri-arrest or arrest clinical condition requiring immediate resuscitation and intervention.

I Resuscitative thoracotomy (before entering operating theatre).

C Survival based on estimated opinion of standard care (tranexamic acid, rapid transport to theatre including an in-theatre thoracotomy).

Mortality (survival to discharge), role of timing of intervention, neurological outcome.

S A systematic review of current literature evaluating resuscitative thoracotomy (defined as a thoracotomy performed either in the pre-hospital environment of emergency department) for patient with intraabdominal injuries.

\section{Methods}

This systematic review was conducted in line with the Preferred Reporting Items for systematic reviews and Meta-Analysis statement [21].

\section{Search strategy}

A comprehensive literature review was conducted by a single author (M.H) which was completed on 24/1/2018. A search of the electronic databases Medline and Embase was conducted using medical subject heading (MESH) terms shown below with the Cochrane database and PROSPERO also being used to identify any completed or ongoing systematic reviews on the subject matter [22]. Finally, Google scholar was searched using broad, non MESH search terms.

- Pre-hospital

- Emergency department

- Ambulance

- Paramedic

- EMS

- Out of hospital

- Abdominal trauma

- Blunt
- Penetrating

- Wound

- Injur*

- Thoracotomy

- Resuscitative thoracotomy

- Emergency thoracotomy

- Trauma

Papers were screened and reviewed based on the eligibility criteria outlined below by a single reviewer. Title of paper, abstract and if required full paper review was used to assess for inclusion. All references in papers were followed up and included where relevant and authors were contacted if any information was unclear.

\section{Eligibility criteria}

All types of studies were included apart from expert opinion, single case reports and review articles (systematic reviews, meta analysis, systematic review). Studies before 1987 were excluded as it was felt that data from more than 30 years ago would not be relevant to current medical practice. Foreign language papers were also excluded as no interpreter was available to ensure any translations were accurate and precise. There was no exclusion on age and therefore any paediatric data was included.

Table 1 gives a summary of inclusion and exclusion criteria. Additional file 1: Appendix 2 contains this summary as well as the perceived weakness these criteria generated.

A single author $(\mathrm{MH})$ evaluated each paper using the CASP checklists and the Cochrane handbook for systematic reviews to assess for validity and reliability [22, 24].If a paper did not answer the first 2 points of the CASP checklist satisfactorily it was marked as a poor-quality study but was still included (see Additional file 1: Appendix 3). The data was extracted by a single reviewer $(\mathrm{MH})$ with all papers being reviewed on two separate occasions to ensure no data was overlooked or misinterpreted.

The following data was extracted for each study which is summarised in Table 1; Title, description of subjects, number of participants, study eligibility criteria, indication for thoracotomy, definition of traumatic cardiac arrest, study design, survival / mortality, neurological outcome, location of intervention (eg emergency department), authors conclusion, timing of intervention.

\section{Results}

Figure 1 demonstrates the Preferred Reporting Items for systematic reviews and meta-analyses (PRISMA) flow diagram for this systematic review.

Seventeen retrospective case studies were included in the review. No meta-analysis was attempted due to the heterogenicity of data both methodological and clinical. Clinically some institutions had clear protocols for performing a 
Table $1 \mathrm{~A}$ table to show the exclusion and inclusion criteria for the study protocol

\begin{tabular}{|c|c|c|}
\hline & Inclusion & Exclusion \\
\hline Study design & $\begin{array}{l}\text { All original research study designs were be included. } \\
\text { Expert opinion and case studies were excluded meaning } \\
\text { all except level } 5 \text { and } 4 \text { evidence will be included as } \\
\text { defined by the oxford centre for evidence-based medicine } \\
\text { [23]. As only original research was reviewed systematic } \\
\text { reviews and literature review was also excluded }\end{array}$ & $\begin{array}{l}\text { Expert opinion } \\
\text { Case studies } \\
\text { Literature review } \\
\text { Systematic review } \\
\text { Editorials }\end{array}$ \\
\hline Study specific details & After 1987 & $\begin{array}{l}\text { Non-English language } \\
\text { Study pre-1987 } \\
\text { Duplicates }\end{array}$ \\
\hline Quality of evidence & Will be evaluated by all included & \\
\hline Resuscitate thoracotomy pre-theatre & $\begin{array}{l}\text { Procedure must be performed in the pre-theatre environment } \\
\text { (ED or pre hospital) }\end{array}$ & In theatre \\
\hline Abdominal trauma & $\begin{array}{l}\text { Must have stated injuries of patients based on either clinical } \\
\text { assessment or in hospital / pre-hospital imaging }\end{array}$ & Isolated chest/ pelvis \\
\hline Outcomes & $\begin{array}{l}\text { Must state outcomes of patients in terms of survival to destination } \\
\text { or discharge. All studies were included if they included either the } \\
\text { primary of secondary outcomes aims. }\end{array}$ & $\begin{array}{l}\text { No patient outcomes } \\
\text { included }\end{array}$ \\
\hline Thoracotomy & Any thoracotomy (clamshell / left lateral) & $\begin{array}{l}\text { Non-thoracotomy } \\
\text { interventions e.g. REBOA }\end{array}$ \\
\hline
\end{tabular}

thoracotomy but not all. Recording of the timing of intervention as well as the patient state at the start of the procedure (e.g. what constituted a loss of signs of life) and clear details of survival to discharge were also variable between studies.

\section{Indications and inclusion}

There was wide variation in the indications for resuscitative thoracotomy with no pre-hospital thoracotomies being included in the review. The indications, exclusion and inclusion criteria for each study are summarised in Additional file 1: Appendix 3. Indications for thoracotomy included patient's in cardiac arrest or who had recently arrested for all types of traumatic injury. There were also differences in timing of thoracotomy being performed ranging from immediately after the onset of cardiac arrest to over $35 \mathrm{~min}$ after. There were several terms used to suggested cardiac arrest in patients including loss of signs of life and the presence of fixed dilated pupils however even these terms were poorly defined with difference between studies as to what constituted a loss of signs of life [25].

\section{Survival to discharge}

The range of survival to discharge for patients undergoing a resuscitative thoracotomy before entering theatre in all studies was $0-16 \%$. This increased to $18 \%$ of 22 patients if only an isolated iliac injury was present [26]. Table 2 summarises all the primary and secondary outcomes. Survival appeared to improve based on the mechanism of injury. The studies that reported survivors demonstrated broadly the same outcomes with isolated abdominal trauma having a better survival rate than polytrauma, penetrating having better outcomes than blunt, and the timing of intervention based on the presence of signs of life, being important.

The widest variation in survival to discharge rates was found in patients with blunt trauma, although It was difficult in several studies to differentiate whether this was isolated abdominal trauma or combined with pelvic trauma and injuries to other locations.

\section{Timings of intervention}

None of the studies included looked specifically at timing of intervention from onset of cardiac arrest or injury and the effect on mortality. Several commented on the improved mortality of those who's arrest was witnessed or occurred within the emergency department, but none were tested and found to be statistically significant. Ongoing CPR was generally a negative predictor of survival in both penetrating and blunt trauma [31]. Several studies demonstrated that the presence of a pulse or even pulseless electrical activity was a positive predictor of survival $[35,37,38]$.

\section{Neurological outcome}

Neurological outcome in patients undergoing a pretheatre thoracotomy was explored in three studies with a wide variety of outcomes. The first study of 252 patients had 4 survivors none of which had any neurological deficit after undergoing pre-theatre thoracotomy for penetrating abdominal and pelvic traumatic injuries [35]. The most negative figure was in a study that looked at patients discharge destination and inferred their neurological status based on this. One of four survivors undergoing a pretheatre thoracotomy had no neurological deficit at time of 


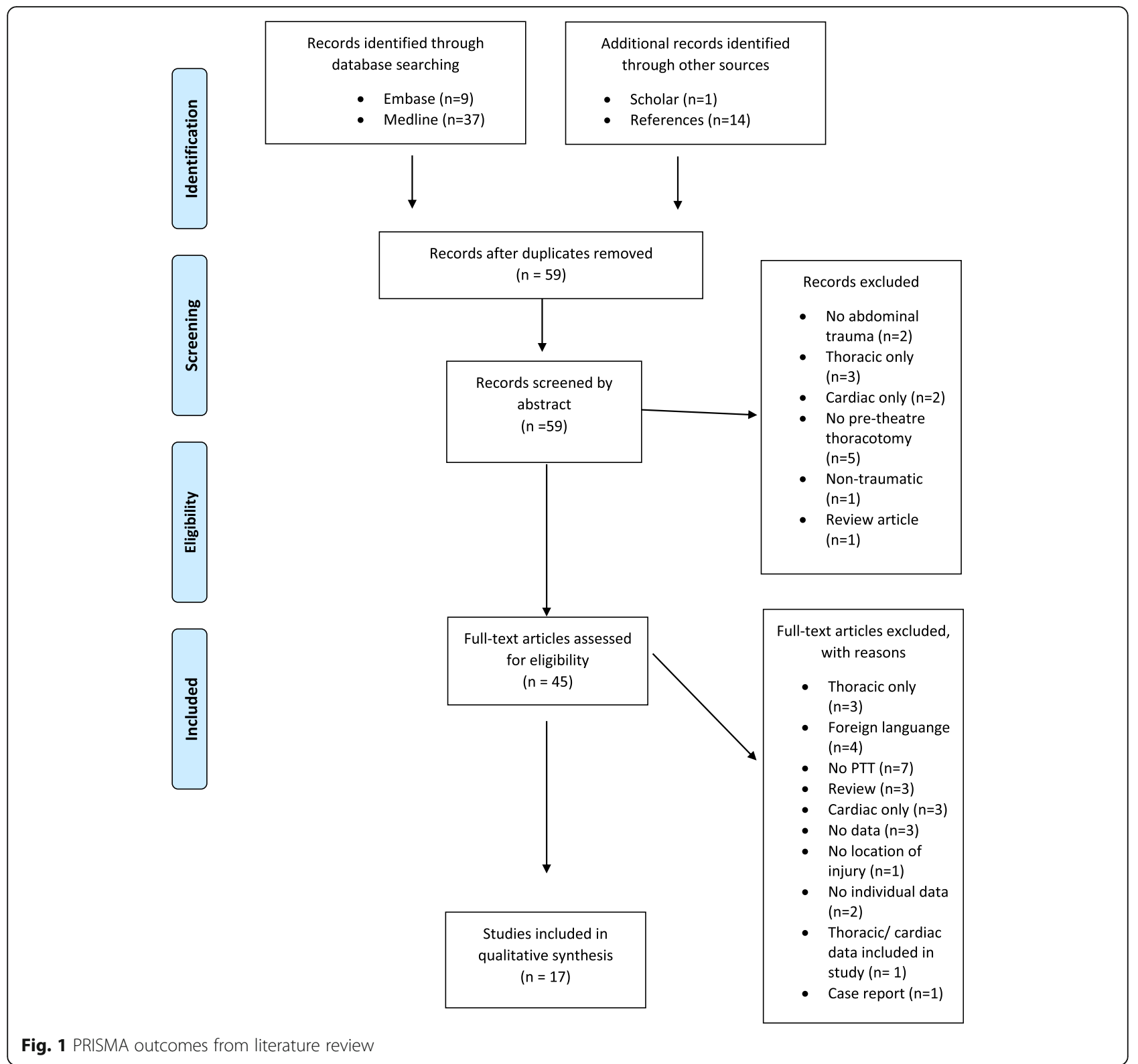

discharge from hospital [36]. A study of 106 patients who survived a thoracotomy demonstrated that $68 \%$ had no permanent neurological deficit, $12 \%$ had a mild neurological deficit and the remaining $20 \%$ were in a persistent vegetative state although this did not separate into abdominal injuries only.

\section{Discussion}

\section{Survival to discharge}

Unfortunately, there was a small number of studies regarding the use of resuscitative thoracotomy for abdominal trauma and the overall quality of the evidence was poor. The initial PICO question focused on contrasting the current management of the peri-arrest or recently arrest trauma patient with abdominal trauma with that of the information gathered from the systematic review. The only information that could be found on outcomes following best current management of abdominal trauma was expert opinion which it is well documented is open to a bias. A systematic review and meta-analysis on the use of emergency department thoracotomy in blunt trauma concluded $1.5 \%$ of patients survived this intervention following a loss of signs of life with the majority having poor neurological outcome at discharge but did not look at specific location of injury [42]. This study still suggested that there may be a role for resuscitative thoracotomy with the chance of survival without it being so poor.

Assuming the expert opinion is accurate then the best probability of survival to discharge for patients with abdominal injuries was in the group who were suffering 
Table 2 A Table to summarise the number of patient's undergoing a resuscitative thoracotomy, the number and percentage (\%) of patients that survived, any comment on neurological outcome and the role of timing of the intervention for each included study

\begin{tabular}{|c|c|c|c|c|c|}
\hline Title & $\begin{array}{l}\text { Number of patients } \\
\text { undergoing pre-theatre } \\
\text { thoracotomy }\end{array}$ & $\begin{array}{l}\text { Number of patients } \\
\text { surviving to } \\
\text { discharge }\end{array}$ & $\begin{array}{l}\text { \% of patients } \\
\text { survival to } \\
\text { discharge }\end{array}$ & $\begin{array}{l}\text { Neurological outcome } \\
\text { (if commented on) }\end{array}$ & $\begin{array}{l}\text { Timing of intervention } \\
\text { (if commented on) }\end{array}$ \\
\hline Velmahos 1995 [27] & $\begin{array}{l}\text { Isolated abdomen } 118 \\
\text { Polytrauma } 501\end{array}$ & $\begin{array}{l}\text { Isolated abdomen } 8 \\
\text { Polytrauma } 1\end{array}$ & $\begin{array}{l}7 \% \\
\text { Less than } 1 \%\end{array}$ & No data & $\begin{array}{l}\text { Best outcomes with } \\
\text { witnessed loss of signs } \\
\text { of life }\end{array}$ \\
\hline Asensio 2003 [26] & 22 & 4 & $18 \%$ & No data & No data \\
\hline Asensio 2005 [28] & 3 & 0 & $0 \%$ & No data & No data \\
\hline Blocksom 2004 [29] & 27 & 3 & $11 \%$ & No data & No data \\
\hline Kalina 2009 [30] & $\begin{array}{l}\text { Isolated abdomen } 7 \\
\text { Polytrauma } 13\end{array}$ & $?$ - unclear & No data & No data & $\begin{array}{l}\text { Presence of signs of life } \\
\text { in field best predictor } \\
\text { of survival }\end{array}$ \\
\hline Moore 2016 [31] & $\begin{array}{l}\text { Isolated abdomen } 116 \\
\text { Polytrauma } 1003\end{array}$ & $\begin{array}{l}\text { Isolated abdomen } 7 \\
\text { Polytrauma } 371\end{array}$ & $\begin{array}{l}6 \% \\
37 \%\end{array}$ & $\begin{array}{l}68 \% \text { no permanent neurological } \\
\text { deficit with } 12 \% \text { mild neurological } \\
\text { deficit and remaining } 20 \% \text { in a } \\
\text { persistent vegetative state }\end{array}$ & $\begin{array}{l}\text { No Pre-hospital CPR } \\
\text { being performed } \\
\text { associated with } \\
\text { better chance of } \\
\text { survival }\end{array}$ \\
\hline Asensio 2007 [32] & 4 & 0 & $0 \%$ & No data & No data \\
\hline Ross 1988 [33] & 7 & 0 & $0 \%$ & No data & No data \\
\hline Nicholas 2003 [34] & 7 & 0 & $0 \%$ & No data & No data \\
\hline Mazzorana 1994 [35] & 252 & 4 & $1.6 \%$ & No neurological deficit & $\begin{array}{l}\text { Improved survival if signs } \\
\text { of life at time of } \\
\text { thoracotomy }\end{array}$ \\
\hline Tyburski 2001 [25] & 31 & 2 & $6 \%$ & No data & No data \\
\hline Moore 2015 [36] & 72 & 4 & $5.5 \%$ & $\begin{array}{l}28.5 \% \text { chance of no neurological } \\
\text { deficit. }\end{array}$ & No data \\
\hline Seamon 2008 [37] & 50 & 8 & $16 \%$ & No neurological deficit & No data \\
\hline Asensio 2001 [38]. & 180 & 50 & $28 \%$ & No data & $\begin{array}{l}\text { Spontaneous breathing } \\
\text { at time of procedure } \\
\text { associated with better } \\
\text { chance of survival }\end{array}$ \\
\hline Asensio 2000 [39]. & 43 & 1 & $2 \%$ & No data & No data \\
\hline Branney 1998 [40]. & $\begin{array}{l}\text { Penetrating abdominal } \\
73 \\
\text { Blunt abdominal } 51\end{array}$ & $\begin{array}{l}8 \\
1\end{array}$ & $\begin{array}{l}10 \% \\
2 \%\end{array}$ & No neurological deficit & $\begin{array}{l}\text { Better outcomes if signs } \\
\text { of life present in pre- } \\
\text { hospital environment }\end{array}$ \\
\hline Lustenberger 2012 [41]. & 31 & 4 & $13 \%$ & No data & No data \\
\hline
\end{tabular}

from unrelenting shock but with a pulse present following penetrating trauma. Based on current management, without a resuscitative thoracotomy before entering an operating theatre survival was $1.7 \%$. All other patterns of injury and worsening states of shock including cardiac arrest had even lower survival to discharge figures without a resuscitative thoracotomy. This is in a population predominantly of young, fit individuals with trauma being the commonest cause of death in the UK within the ages of 1-40 [43]. This can be compared to the survival to discharge from medical cardiac arrest in the UK which is 8.6\% [44]. The last major intervention to improve mortality in trauma care was the widespread use of tranexamic acid in trauma patients which although an undoubted break through still leaves an unacceptably high mortality particularly in the context of managing young, healthy individuals [45].
The use of pre-laparotomy thoracotomy in theatre was strongly advocated by several studies as a method of improving overall survival and was proven to be statistically significant $[25,38]$. This suggests that the intervention its self with cross clamping of the aorta is effective but perhaps it is the timing based on the patients physiology that is important.

A literature review including 640 patient's with isolated abdominal injuries and 590 patient's suffering from polytrauma undergoing a resuscitative thoracotomy before theatre suggested similar findings to those in the systematic review [46]. It reported a survival of $4.5 \%$ in isolated abdominal injury and $0.7 \%$ in polytrauma.

The presence and loss of signs of life was explored in most studies suggesting the importance of the patients clinical condition at the time of intervention. Although there was wide variety of practice in the indications and 
use of resuscitative thoracotomy, the majority were performed once a patient had lost cardiac output. This clearly has a bearing on the interpretation of the results as the majority of patients suffering a traumatic cardiac arrest are highly unlikely to survive making even small improvement in mortality significant. Other large studies looking at resuscitative thoracotomy for blunt trauma have suggested the lack of electrical activity is a negative predictor of mortality and no intervention should be performed if cardiac electrical activity is absent [47].

There is no unifying definition of a resuscitative thoracotomy with varying terms for thoracotomies performed within the emergency department making the initial literature search problematic leaving the potential for some studies to have been omitted, thus affected the overall reliability and validity of the study. Another consideration not assessed was clinicians discretion to perform intervention based on other factors such as a patients co-morbidities. Although the use of protocols may aid decision making the final decision whether to perform an intervention lies with the physician and thus will be open to individual interpretation.

\section{Timing of intervention}

The longer patients went without intervention the worse the outcome was, in the studies that analysed this however no statistically significant finding about the exact time was suggested in any of the papers. A large literature review of resuscitative thoracotomy found that outcomes were improved if the patient arrested in front of the physician performing the thoracotomy or in the recent past (eg en route to hospital) [46]. This finding is mirrored in the use of thoracotomy for thoracic trauma with universally poor outcomes the longer the patient is in cardiac arrest [4]. This correlates with findings that suggest that hypovolemic induced asystole is almost a universally un survivable event and thus the earlier cross clamping of the aorta and therefore control of haemorrhage can occur the higher the potential for survival [1]. However particularly in the peri-arrest patient is in important to note that intervention too early could have a detrimental effect on an already physiological deplete patient and a balance should be struck if possible. There is no guide as to an intervention cut off threshold such as a systolic blood pressure and decision for intervention must be made after a rapid thorough evaluation of the patient and based on the full clinical picture.

\section{Neurological outcome}

Only 3 studies investigated or commented on the neurological outcome of survivors to discharge [31, 36, 37, 46]. A literature review of a much larger group of patients, but also more variety in indications and injuries, reported that $92.4 \%$ of survivors had no neurological deficit but did not quantify what exactly this meant [46]. Although in the UK in the year $201791 \%$ of patients with an injury severity score of over 9 survived to discharge their neurological status at that point was not recorded and thus makes comparison difficult [48]. Internationally one Australian study assessed 3824 patients who had an injury severity score of 15 or above 12 months after their injuries, $80 \%$ of patients reported some degree of neurological dysfunction [49]. The paediatric population suffering from a traumatic cardiac arrest has been assessed by a large systematic review which demonstrated as high as $44.3 \%$ of survivors had a good neurological outcome at discharge [50]. A large systematic review assessing neurological outcomes in 1369 patient undergoing thoracotomy for blunt traumatic cardiac arrest found $1.5 \%$ of patients survived with a good neurological outcome with vital signs being present either in the ED or on scene and CPR on going for no longer than 15 minutes [42].

\section{Weakness of study}

The main weakness in this study was the lack of a control group for comparison with the intervention group. The outcomes of a patient with abdominal trauma and unrelenting shock either in, or close to, cardiac arrest not undergoing a resuscitative thoracotomy is largely unknown and thus expert opinion was used to provide comparison. The study therefore relies on this information being accurate to try and draw comparisons and thus conclusions, which, given the known bias associated with expert opinion questions the overall validity of the study. All the papers included were retrospective cohort studies with no randomisation and thus the potential for selection bias. This was potentially further compounded as the investigators were not blinded and therefore gives a risk of measurement bias. Although this is unlikely to be a problem when assessing 30 day mortality with the secondary outcomes of the study this may have had some bearing. The majority of the data collection occurred at large level 1 trauma centre's within the united states. It is not unreasonable to question not only performance bias when compared to studies published outside the large trauma centre's but also the applicability to the UK patient population and practices. Ideally a more controlled study should be performed with a clear indication for intervention with randomisation to groups with blinding of researchers to increase overall validity of the findings. This however would be a difficult if not impossible task. Practically, in the UK, a pre-alert from the ambulance service may be forth coming with accurate information about the patients en route to hospital however this is often not the case with key details that affect decision making being omitted [51]. In the prehospital environment information from the public is even more unreliable meaning randomisation decisions 
would need to be made at the time of patient assessment in a very stressful environment [52]. Although possible, timing would be important, and management would rely on the correct equipment and skills set being available immediately which would likely lead to low numbers of patients being recruited. There would also be ethical considerations when dealing with patients as randomised to the non-treatment group, based on the estimated survival probabilities, would also certainly be a death sentence. Alternatives to improve validity for future trials would be the use of case matching when conducting retrospective case reviews however in institutions with a clear thoracotomy policy, finding those that did not undergo the procedure would be challenging.

This study has a number of limitations when looking specifically at the research question. Although the primary aim of the study was to look at outcomes following abdominal trauma, patients suffering with polytrauma were also included. This decreases the overall validity of the findings particularly guiding application within the clinical environment when faced with a patient with isolated abdominal trauma. The exclusion of foreign language papers also has the potential to lead to missing data which when dealing with the small numbers described could have an influence on the conclusions drawn.

\section{Future developments}

The use of resuscitative thoracotomy has been documented for many years however new technologies are in development. One of the aims of a thoracotomy in nonthoracic trauma is to cross clamp the descending aorta and achieve haemorrhage control. Resuscitative endovascular balloon occlusion of the aorta (REBOA) aims to achieve control of haemorrhage with a less invasive approach. Although it is in the early stage of development is has already been used in the pre-hospital environment as well as trauma centres within the UK [53]. However, studies are yet to show a demonstrable benefit when compared to resuscitative thoracotomy [54, 55]. One comparison study suggested a mortality benefit when compared to resuscitative thoracotomy however those undergoing REBOA were less haemodynamically unstable and REBOA took longer to perform [36].

Resuscitative thoracotomy for abdominal trauma is and will remain a controversial and divisive procedure. Although the evidence is of low quality it is difficult to see how higher levels of evidence, such as randomised control trials, will ever be put into place given the ethical implications and controversy surrounding practice. With experts suggesting a survival rate, with current management strategies, at best $1.7 \%$. In the population in which trauma has the highest prevalence, namely young fit individuals, this is unacceptable when compared to medical cardiac arrest survival of $8.6 \%$. Newer, more targeted interventions are in development however the current evidence is sparse and suggests at best equal outcomes when compared to thoracotomy.

\section{Conclusion}

Although a highly controversial, invasive and arguably last-ditch effort procedure, pre-theatre thoracotomy should be considered in the peri-arrest or arrested patient with abdominal trauma either in isolation or as part of polytrauma. The best outcomes are achieved with patients not in cardiac arrest or who have recently arrested and who do not have a head injury present. The earlier the intervention can be performed, the better the outcome for patients, with survival figures of up to $18 \%$ with intervention compared to $0.001 \%$ without, however more high quality evidence is require to demonstrate a definite mortality benefit for patients.

\section{Supplementary information}

Supplementary information accompanies this paper at https://doi.org/10. 1186/s13049-020-0705-4.

Additional file 1: Appendix's: Outcomes following resuscitative thoracotomy for abdominal exsanguination, a systematic review

Acknowledgements

Queen Mary University of London.

School of Surgery, Health Education Yorkshire and Humber, Health Education England.

Authors' contributions

$\mathrm{MH}$ - Conception, analysis, interpretation, draft. ZP - Substantially revised manuscript. Both authors read and approved the final manuscript.

Funding

Nil to report.

Availability of data and materials

Separate uploaded document.

Ethics approval and consent to participate

NA.

Consent for publication

NA.

Competing interests

The authors declare that they have no competing interests.

Author details

${ }^{1}$ Scarborough Hospital, York Teaching Hospital NHS Trust, Woodlands drive, Scarborough YO12 6QL, UK. '2Queen Mary University, London E1 4NS, UK.

Received: 28 September 2019 Accepted: 19 January 2020

Published online: 06 February 2020

References

1. Lockey D, Crewdson K, Davies G. Traumatic cardiac arrest: who are the survivors? Ann Emerg Med. 2006;48(3):240-4.

2. Georgescu V, Tudorache $O$, Nicolau M, Strambu V. Study regarding the survival of patients suffering a traumatic cardiac arrest. J Med Life. 2015; 8(Spec Issue):103. 
3. European resuscitation council. Pre-hospital resuscitation. 2015. Accessed online 03/18 at: https://www.resus.org.uk/resuscitation-guidelines/ prehospital-resuscitation/

4. Davies GE, Lockey DJ. Thirteen survivors of prehospital thoracotomy for penetrating trauma: a prehospital physician-performed resuscitation procedure that can yield good results. J Trauma. 2011;70:E75-8.

5. Lockey DJ, Davies G. Pre-hospital thoracotomy: a radical resuscitation intervention come of age? Resuscitation. 2007;75:394-5.

6. Truhlar A, Deakin CD, Soar J, et al. European resuscitation council guidelines for resuscitation 2015 section 4 cardiac arrest in special circumstances. Resuscitation. 2015;95:147-200.

7. Lockey DJ, Lyon RM, Davies GE. Development of a simple algorithm to guide the effective management of traumatic cardiac arrest. Resuscitation. 2013;84:738-42.

8. Moore EE, Knudson MM, Burlew CC, Inaba K, Dicker RA, Biffl WL, Malhotra AK, Schreiber MA, Browder TD, Coimbra R, et al. Defining the limits of resuscitative emergency department thoracotomy: a contemporary Western Trauma Association perspective. J Trauma. 2011;70:334-9.

9. Ledgerwood AM, Kazmers M, Lucas CE. The role of thoracic aortic occlusion for massive hemoperitoneum. J Trauma. 1976;16(08):610-5.

10. Smith JE, Rickard A, Wise D. Traumatic cardiac arrest. J R Soc Med. 2015; 108(1):11-6.

11. Pande R, Saratzis A, Winter Beatty J, Doran C, Kirby R, Harmston C. Contemporary characteristics of blunt abdominal trauma in a regional series from the UK. Ann R Coll Surg Engl. 2017;99(1):82-7.

12. Clarke JR, Trooskin SZ, Doshi PJ, Greenwald L, Mode CJ. Time to laparotomy for intra-abdominal bleeding from trauma does affect survival for delays up to 90 minutes. J Trauma Acute Care Surg. 2002;52(3):420-5.

13. Harvin JA, Maxim T, Inaba K, Martinez-Aguilar MA, King DR, Choudhry AJ, Zielinski MD, Akinyeye S, Todd SR, Griffin RL, Kerby JD. Mortality after emergent trauma laparotomy: a multicenter, retrospective study. J Trauma Acute Care Surg. 2017:83(3):464-8.

14. Marsden M, Carden R, Navaratne L, Smith IM, Penn-Barwell JG, Kraven LM, Brohi K, Tai NR, Bowley DM. Outcomes following trauma laparotomy for hypotensive trauma patients: a UK military and civilian perspective. J Trauma Acute Care Surg. 2018;85(3):620-5.

15. Clevenger FW, Yarbrough DR, Reines HD. Resuscitative thoracotomy: the effect of field time on outcome. J Trauma. 1988;28:441-5.

16. Coats TJ, Keogh S, Clark H, Neal M. Prehospital resuscitative thoracotomy for cardiac arrest after penetrating trauma: rationale and case series. J Trauma. 2001;50:670-3.

17. Narvestad JK, Meskinfamfard M, Søreide K. Emergency resuscitative thoracotomy performed in European civilian trauma patients with blunt or penetrating injuries: a systematic review. Eur J Trauma Emerg Surg. 2016;42(6):677-85.

18. Baker CC, Caronna JJ, Trunkey DD. Neurologic outcome after emergency room thoracotomy for trauma. Am J Surg. 1980;139(5):677-81.

19. Shimazu SE, Shatney $\mathrm{CH}$. Outcomes of trauma patients with no vital signs on hospital admission. The Journal of trauma. 1983;23(3):213-6.

20. Seamon MJ, Haut ER, Van Arendonk K, Barbosa RR, Chiu WC, Dente CJ, Fox N, Jawa RS, Khwaja K, Lee JK, Magnotti LJ. An evidence-based approach to patient selection for emergency department thoracotomy: a practice management guideline from the eastern Association for the Surgery of trauma. J Trauma Acute Care Surg. 2015:79(1):159-73.

21. National institute for health research. International prospective register of systematic reviews (PROSPERO). Accessed online 11/17 at: https://www.crd. york.ac.uk/prospero/.

22. Cochrane Collaborative Cochrane Handbook for Systematic reviews of interventions. V5.1.0 Accessed online 11/17 at: http://handbook.cochrane.org/.

23. Centre for evidence based medicine, Oxford university (online) Accessed 11/17 at: http://www.cebm.net/oxford-centre-evidence-based-medicinelevels-evidence-march-2009/.

24. Critical appraisal skills programme checklists. Accessed online 11/17 at: http://www.casp-uk.net/casp-tools-checklists.

25. Tyburski JG, Wilson RF, Dente C, Steffes C, Carlin AM. Factors affecting mortality rates in patients with abdominal vascular injuries. J Trauma Acute Care Surg. 2001;50(6):1020-6.

26. Asensio JA, Petrone P, Roldán G, Kuncir E, Rowe VL, Chan L, Shoemaker W, Berne TV. Analysis of 185 iliac vessel injuries: risk factors and predictors of outcome. Arch Surg. 2003;138(11):1187-94.

27. Velmahos GC, Degiannis MD, Allwood AC, Saadia R. Outcome of a strict policy on emergency department thoracotomies. Arch Surg. 1995;130:774-7.
28. Asensio JA, Petrone P, Kimbrell B, Kuncir E. Lessons learned in the management of thirteen celiac axis injuries. South Med J. 2005:98(4):462-7.

29. Blocksom JM, Tyburski JG, Sohn RL, Williams M. Prognostic determinants in duodenal injuries/DISCUSSION. Am Surg. 2004;70(3):248.

30. Kalina M, Teeple E, Fulda G. Are there still selected applications for resuscitative thoracotomy in the emergency department after blunt trauma? Del Med J. 2009;81(5):195-8.

31. Moore HB, Moore EE, Burlew CC, Biffl WL, Pieracci FM, Barnett CC, Bensard DD, Jurkovich GJ, Fox CJ, Sauaia A. Establishing benchmarks for resuscitation of traumatic circulatory arrest: success-to-rescue and survival among 1,708 patients. J Am Coll Surg. 2016;223(1):42-50.

32. Asensio JA, Petrone P, Garcia-Nuñez L, Healy M, Martin M, Kuncir E. Superior mesenteric venous injuries: to ligate or to repair remains the question. $J$ Trauma Acute Care Surg. 2007;62(3):668-75.

33. Ross SE, Schwab CW. Resuscitation of subdiaphragmatic exsanguination. Am Surg. 1988;54(4):200-3.

34. Nicholas JM, Rix EP, Easley KA, Feliciano DV, Cava RA, Ingram WL, Parry NG Rozycki GS, Salomone JP, Tremblay LN. Changing patterns in the management of penetrating abdominal trauma: the more things change, the more they stay the same. J Trauma Acute Care Surg. 2003;55(6):1095-110.

35. Mazzorana V, Smith RS, Morabito DJ, Brar HS. Limited utility of emergency department thoracotomy. Am Surg. 1994;60(7):516-20.

36. Moore L, Brenner M, Kozar RA, Pasley J, Wade CE, Baraniuk MS, Scalea T, Holcomb JB. Implementation of resuscitative endovascular balloon occlusion of the aorta as an alternative to resuscitative thoracotomy for noncompressible truncal hemorrhage. J Trauma Acute Care Surg. 2015;79(4):523-32.

37. Seamon MJ, Pathak AS, Bradley KM, Fisher CA, Gaughan JA, Kulp H, Pieri PG, Santora TA, Goldberg AJ. Emergency department thoracotomy: still useful after abdominal exsanguination? J Trauma Acute Care Surg. 2008;64(1):1-8.

38. Asensio JA, McDuffie L, Petrone P, Roldán G, Forno W, Gambaro E, Salim A, Demetriades D, Murray J, Velmahos G, Shoemaker W. Reliable variables in the exsanguinated patient which indicate damage control and predict outcome. Am J Surg. 2001;182(6):743-51.

39. Asensio JA, Chahwan S, Hanpeter D, Demetriades D, Forno W, Gambaro E, Murray J, Velmahos G, Marengo J, Shoemaker WC, Berne TV. Operative management and outcome of 302 abdominal vascular injuries. Am J Surg. 2000;180(6):528-34.

40. Branney SW, Moore EE, Feldhaus KM, Wolfe RE. Critical analysis of two decades of experience with postinjury emergency department thoracotomy in a regional trauma center. J Trauma Acute Care Surg. 1998:45(1):87-94

41. Lustenberger T, Labler L, Stover JF, Keel MJ. Resuscitative emergency thoracotomy in a Swiss trauma Centre. Br J Surg. 2012;99(4):541-8.

42. Slessor D, Hunter $\mathrm{S}$. To be blunt: are we wasting our time? Emergency department thoracotomy following blunt trauma: a systematic review and meta-analysis. Ann Emerg Med. 2015;65(3):297-307.

43. The Trauma and Audit research network. The Trauma and audit research network overview. Accessed online 04/18 at: https:/www.tarn.ac.uk/ content/images/53/Overview\%2006.pdf

44. Resuscitation council. Consensus paper on out of hospital cardiac arrest (2014) Accessed online 04/18 at: https://www.resus.org.uk/publications/ consensus-paper-on-out-of-hospital-cardiac-arrest-in-england/

45. Crash-2 Collaborators. The importance of early treatment with tranexamic acid in bleeding trauma patients: an exploratory analysis of the CRASH-2 randomised controlled trial. Lancet. 2011;377(9771):1096-101.

46. Rhee PM, Acosta J, Bridgeman A, et al. Survival after emergency department thoracotomy: review of published data from the past 25 years. J Am Coll Surg. 2000;190:288-98.

47. Battistella FD, Nugent W, Owings JT, Anderson JT. Field triage of the pulseless trauma patient. Arch Surg. 1999;134(7):742-6.

48. Moran CG, Lecky F, Bouamra O, Lawrence T, Edwards A, Woodford M, Willett $\mathrm{K}$, Coats TJ. Changing the system-major trauma patients and their outcomes in the NHS (England) 2008-17. EClinicalMedicine. 2018;2:13-21.

49. Gabbe BJ, Biostat GD, Simpson PM, Sutherland AM, Dip G, Wolfe R, Fitzgerald MC, Judson R, Cameron PA. Improved functional outcomes for major trauma patients in a regionalized, inclusive trauma system. Ann Surg. 2012;255(6):1009-15.

50. Zwingmann J, Mehlhorn AT, Hammer T, Bayer J, Südkamp NP, Strohm PC Survival and neurologic outcome after traumatic out-of-hospital cardiopulmonary arrest in a pediatric and adult population: a systematic review. Crit Care. 2012;16(4):R117.

51. Brown R, Warwick J. Blue calls_-time for a change? Emerg Med J. 2001; 18(4):289-92. 
52. Higgins J, Wilson S, Bridge P, Cooke MW. Communication difficulties during 999 ambulance calls: observational study. Bmj. 2001;323(7316):781-2.

53. London's air ambulance. Accessed online 04/18 at: https://

londonsairambulance.co.uk/our-service/news/2014/06/we-perform-worldsfirst-pre-hospital-reboa

54. Nunez RM, Naranjo MP, Foianini E, Ferrada P, Rincon E, García-Perdomo HA, Burbano P, Herrera JP, García AF, Ordoñez CA. A meta-analysis of resuscitative endovascular balloon occlusion of the aorta (REBOA) or open aortic cross-clamping by resuscitative thoracotomy in non-compressible torso hemorrhage patients. World J Emerg Surg. 2017 Dec;12(1):30.

55. Renna MS, van Zeller C, Abu-Hijleh F, Tong C, Gambini J, Ma M. A one-year cost-utility analysis of REBOA versus RTACC for non-compressible torso haemorrhage. Trauma. 2017;24:1460408617738810.

\section{Publisher's Note}

Springer Nature remains neutral with regard to jurisdictional claims in published maps and institutional affiliations.

Ready to submit your research? Choose BMC and benefit from:

- fast, convenient online submission

- thorough peer review by experienced researchers in your field

- rapid publication on acceptance

- support for research data, including large and complex data types

- gold Open Access which fosters wider collaboration and increased citations

- maximum visibility for your research: over $100 \mathrm{M}$ website views per year

At BMC, research is always in progress.

Learn more biomedcentral.com/submissions 